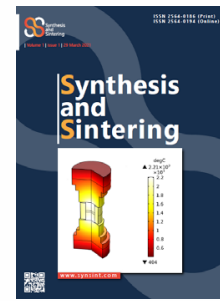

\title{
Effects of carbon nano-additives on characteristics of TiC ceramics prepared by field-assisted sintering
}

\author{
Shapour Jafargholinejad ${ }^{\text {a,*}}$, Soheyl Soleymani ${ }^{\text {b }}$ \\ ${ }^{a}$ Department of Mechanical Engineering, York University, Toronto, ON, Canada \\ ${ }^{b}$ Imperial Oil,602 Christina Street S., Sarnia, Ontario, Canada
}

\section{A B S T R A C T}

Five carbonaceous nano-additives (graphite, graphene, carbon black, carbon nanotubes, and diamond) had different impacts on the sinterability, microstructural evolution, and properties of titanium carbide. In this research, the sintering by spark plasma was employed to produce the monolithic TiC and carbon-doped ceramics under the sintering parameters of $1900{ }^{\circ} \mathrm{C}, 10 \mathrm{~min}$, $40 \mathrm{MPa}$. The carbon black additive had the best performance in densifying the TiC, thanks to its fine particle size, as well as its high chemical reactivity with $\mathrm{TiO}_{2}$ surface oxide. By contrast, the incorporation of nano-diamonds resulted in a considerable decline in the relative density of $\mathrm{TiC}$ owing to the graphitization phenomenon, together with the gas production at high temperatures. Although carbon precipitation from the TiC matrix occurred in all samples, some of the added carbonaceous phases promoted this phenomenon, while the others hindered it to some extent. Amongst the introduced additives, carbon black had the most contribution to grain refining, so that a roughly halved average grain size was attained in comparison with the undoped specimen. The highest values of hardness $\left(3233 \mathrm{HV}_{0.1 \mathrm{~kg}}\right)$, thermal conductivity $(25.1$ $\mathrm{W} / \mathrm{mK}$ ), and flexural strength ( $658 \mathrm{MPa}$ ) secured for the ceramic incorporated by $5 \mathrm{wt} \%$ nano carbon black

(C) 2021 The Authors. Published by Synsint Research Group.
KEYWORDS

Titanium carbide

Carbon additive

Nanomaterials

Spark plasma sintering

Characterization

\section{Introduction}

As a well-known ultra-high-temperature ceramic (UHTC), titanium carbide $(\mathrm{TiC})$ has a wide range of physical and mechanical characteristics, e.g., low neutron absorption cross-section, excellent hardness, high thermal resistivity, superior melting point $\left(3160{ }^{\circ} \mathrm{C}\right)$, high chemical stability, and low density [1-4]. Offering such outstanding properties has made this ceramic as an excellent nomination for many high-temperature structural applications, particularly in automotive, nuclear, defense, and aerospace industrial ends [5-8]. Against all the above-mentioned terrific features, TiC has a poor sinterability owing to its low self-diffusion coefficient and rebuts covalent bonding, which makes its sinterability challenging [9-12]. On the other hand, if a higher sintering temperature is used to deal with these limitations, deterioration of mechanical properties may happen as a result of grain coarsening [13-15]. Therefore, other solutions should be taken into account.

As two potential replacements for the conventional powder metallurgy technique, many researches have been done on fabricating TiC-based materials using spark plasma sintering (SPS) [16-18] or hot pressing (HP) $[19,20]$ routes. The former takes advantage of external pressure over the sintering process through which the densification can be completed at a roughly low sintering temperature within a short dwelling time [21,22]. Of course, the occurring spark amongst the available particles is also a key factor in decreasing the required sintering temperature and soaking time in this fantastic sintering process [23]. By contrast, some other investigators have tried to

* Corresponding author. E-mail address: shapoor.jafargolinejad@gmail.com (S. Jafargholinejad)

Received 19 April 2021; Received in revised form 28 April 2021; Accepted 30 April 2021.

Peer review under responsibility of Synsint Research Group. This is an open access article under the CC BY license (https://creativecommons.org/licenses/by/4.0/). https://doi.org/10.53063/synsint.2021.1123 
promote the sinterability and mechanical-physical characteristics of TiC via introducing some suitable sintering additives [24,25].

Nguyen et al. [26] studied the SPSed TiC materials incorporated by graphene nano-platelets. According to the relative density results, it seems that the role of graphene in removing the residual porosity of $\mathrm{TiC}$ had been trivial. However, the presence of such an additive within the microstructure could participate in the eradication of the $\mathrm{TiO}_{2}$ surface layer over the sintering process. As a result of this contribution, as well as the impact of graphene in grain refining of the titanium carbide matrix, an increment happened in the bending strength of the TiC-graphene ceramic. Fattahi et al. [27] strengthened $\mathrm{TiC}$ by introducing nano-graphite into the TiC matrix. They used the SPS method as the manufacturing route in which the samples sintered at $1900{ }^{\circ} \mathrm{C}$. The presence of graphite could improve the sinterability of $\mathrm{TiC}$, attaining a relative density of $>97 \%$. Although the hardness of the TiC-graphite specimen showed a noticeable drop compared to the monolithic $\mathrm{TiC}$, the bending strength of the ceramic composite was considerably improved, standing next to $630 \mathrm{MPa}$. The influence of carbon black on the sinterability of titanium carbide was found to be impressive so that a fully dense part was achieved by incorporating carbon black (5 wt \%) to titanium carbide [28]. In addition, the carbon black incorporation could noticeably refine the microstructure of the matrix. Accordingly, all hardness, thermal conductivity, and flexural strength features were prompted in the TiC-carbon black ceramic in compared to the undoped TiC. Finally, Nguyen et al. studied the TiCdiamond system sintered by the SPS method. Although this additive worsened all relative density, bending strength and hardness of titanium carbide, its influence on the thermal conductivity of titanium carbide was remarked. According to their outcome, the diamond additive could improve the thermal conductivity of titanium carbide by almost $30 \%$, standing next to $23 \mathrm{~W} / \mathrm{mK}$.

This comparative research intends to compare the effect of different carbonaceous compounds, i.e., graphite, graphene, carbon black, carbon nanotubes (CNTs), and nano-diamonds, on the microstructure, physical-mechanical features, and sinterability of titanium carbide. All specimens were SPSed under similar sintering circumstances at 1900 ${ }^{\circ} \mathrm{C}$ for $10 \mathrm{~min}$ under $40 \mathrm{MPa}$. Next, they were examined using X-ray diffractometry (XRD), and field emission scanning electron microscopy (FESEM). Additionally, the thermal conductivity, relative density, bending strength, and Vickers hardness of all specimens were measured/calculated, comparing to each other.

\section{Experimental method}

\subsection{Starting substances}

The first-rate titanium carbide, graphite, graphene, carbon black, carbon nanotubes (CNTs), and nano-diamonds materials were purchased as the starting powders. The details of these powder materials are given in Table 1 . Additionally, Table 2 presents the designed samples aimed to be produced in this examination. At first, a digital scale was used to weigh the initial materials based on Table 2 . Next, each powder sample was ultrasonically scattered in an ethanol environment for $30 \mathrm{~min}$. Afterward, the arranged slurries were heated at $120{ }^{\circ} \mathrm{C}$ on a hot-plate shaker for $120 \mathrm{~min}$ to provide an excellent mixing, as well as withdrawing the ethanol. Subsequently, a universal oven was implemented to dehumidify the slurries for 24 hours at 100 ${ }^{\circ} \mathrm{C}$. The dried powder specimens were smashed in an agate mortar, and
Table 1. The as-received materials used in this research as the starting powders.

\begin{tabular}{ccc}
\hline Starting powders & Purity & Material size \\
\hline TiC & $98.5 \%$ & $<12 \mu \mathrm{m}$ \\
\hline Graphite nano-flakes & $99 \%$ & $<100 \mathrm{~nm}$ \\
\hline & & Less than 32 layers \\
Graphene nano-platelets & $99 \%$ & $\begin{array}{c}\text { Diameter }<12 \mu \mathrm{m} \\
\text { Thickness }<18 \mathrm{~nm}\end{array}$ \\
& & $<30 \mathrm{~nm}$ \\
\hline Carbon black & $98.5 \%$ & Tube; length: $\sim 50 \mu \mathrm{m}$ \\
\hline \multirow{2}{*}{$\begin{array}{c}\text { Carbon nanotubes } \\
\text { (CNTs) }\end{array}$} & $98 \%$ & inner diameter: $3-5 \mathrm{~nm}$ \\
& & outer diameter: $5-15 \mathrm{~nm}$ \\
\hline Nano-diamond & $98.3 \%$ & $<10 \mathrm{~nm}$ \\
\hline
\end{tabular}

Table 2. The composition of produced specimens, together with the relevant coding system.

\begin{tabular}{cc}
\hline Code & composition \\
\hline $\mathrm{T}$ & $\mathrm{TiC}$ \\
\hline $\mathrm{TC}_{\mathrm{Gt}}$ & $\mathrm{TiC}-5 \mathrm{wt} \%$ graphite \\
\hline $\mathrm{TC}_{\mathrm{Gn}}$ & $\mathrm{TiC}-5 \mathrm{wt} \%$ graphene \\
\hline $\mathrm{TC}_{\mathrm{B}}$ & $\mathrm{TiC}-5 \mathrm{wt} \%$ carbon black \\
\hline $\mathrm{TC}_{\mathrm{NTs}}$ & $\mathrm{TiC}-5 \mathrm{wt} \%$ carbon nanotubes \\
\hline $\mathrm{TC}_{\text {Diamond }}$ & $\mathrm{TiC}-5 \mathrm{wt} \%$ nano-diamonds \\
\hline
\end{tabular}

then, passed by a sieve (mesh of 100) to attain uniform mixtures. The sintering mold was made of graphite, lined by thin graphite sheets to lessen the possibility of reactions between it and the powder mixtures during the sintering process. After loading each prepared powder sample into the abovementioned graphite die, individually, the sintering process was performed for $10 \mathrm{~min}$ under $40 \mathrm{MPa}$ at $1900{ }^{\circ} \mathrm{C}$ using an SPS machine. The as-sintered samples were gradually cooled down to the room temperature in the SPS chamber, and thereafter, they were ground to have the graphite line removed.

\subsection{Characterization}

The rule of mixture and Archimedes principle were exploited to calculate/measure the theoretical and bulk densities, respectively. The ratio of the latter to the former kind of density was mentioned as the relative density of each ceramic. The phase study on the SPSed samples was carried out by an XRD device, respectively. Besides, an FESEM used in this examination to assess the microstructures. The Image software (Ver. 1.52a) was utilized to estimate average grain size, and thermodynamic evaluations were fulfilled using the HSC program (Ver. 6). Vickers hardness of every sample was quantified by indenting a weight of $100 \mathrm{~g}$ on the polished sections (six indentations on average). Also, a universal testing machine was used to meter the threepoint flexural strength of as-prepared ceramics. Finally, the thermal conductivity of samples was determined using a conductivity meter. 


\section{Results and discussion}

\subsection{Phase assessment and sinterability}

According to the TiC powder (not shown here), it can be seen that only peaks attributed to the $\mathrm{TiC}$ compound could be detected, indicating the low content of possible unwanted phases. According to the literature, it is a fact that the surface of the TiC particles can easily be oxidized thanks to the high reactivity of titanium element with the oxygen accessible within the atmosphere. Such oxide not only prevents a powerful bonding between two adjacent TiC particles but also may result in grain coarsening during the sintering. Therefore, if a sintering aid can remove this surface oxide, an improvement would happen in the relative density of TiC. Carbonaceous phases can play such a role in the TiC system. As the morphology and crystalline structure of the various carbon forms used in this examination were different, their impacts on the sinterability and characteristics of the final ceramics can be varied. In the following paragraphs, each specimen will be studied in terms of relative density and sintering behavior.

Fig. 1 shows the effect of various carbonaceous phases on the relative density of titanium carbide. As is clear, the monolithic TiC arrived at a relative density of $>95 \%$, which was an acceptable value for a sintering aid-free TiC ceramic. Amongst the different carbon forms examined in this research, the influence of carbon black was the most significant, obtaining a relative density of $100 \%$. Although graphene nanoplatelets had no noticeable influence on the relative density of TiC, graphite nanoflakes could enhance this value by around $1.5 \%$, standing next to $97 \%$. However, both carbon nanotubes (CNTs) and diamond worsened the relative density of $\mathrm{TiC}$, resulted in relative density values of $92.1 \%$ and $90.3 \%$, respectively.

Fig. 2 differentiates the XRD spectra of the as-produced samples. Looking at the XRD model of the $\mathrm{T}$ specimen, three different phases could be detected: $\mathrm{TiC}, \mathrm{Ti}_{6} \mathrm{C}_{3.75}$, and graphite. So, it can be concluded that some carbon atoms departed the $\mathrm{TiC}$ structure, precipitating within the $\mathrm{TiC}$ matrix. Non-stoichiometric $\mathrm{TiC}_{\mathrm{x}}$ is considered as a challenging material, which its mechanical and electrical properties are governed

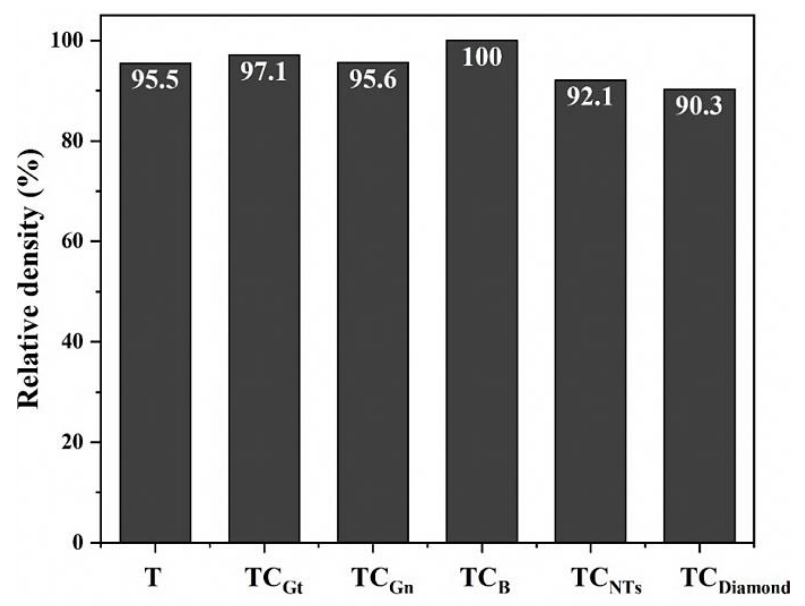

Fig. 1. Relative densities of the $\mathrm{T}, \mathrm{TC}_{\mathrm{Gt}}, \mathrm{TC}_{\mathrm{Gn}}, \mathrm{TC}_{\mathrm{B}}, \mathrm{TC}_{\mathrm{NTs}}$, and $\mathrm{TC}_{\text {Diamond }}$ specimens. by the value of $x$, varying within the range of 0.5-1 [29]. Based on this fact, the non-stoichiometric $\mathrm{TiC}_{\mathrm{x}}$ could show different morphology, bulk modulus, hardness, densification behavior, and grain size depending on the $\mathrm{C} / \mathrm{Ti}$ ratio [30]. The crystalline lattice of $\mathrm{TiC}_{\mathrm{x}}$ is NaCl-type (B1) and carbon atoms have placed at the octahedral positions, while the face-centered spots are occupied by the titanium atoms. When some of the carbon atoms leave their locations, the resulted disordered phase is called non-stoichiometric $\mathrm{TiC}_{\mathrm{x}}$ [31]. Therefore, it seems that the harsh conditions under the spark plasma sintering have forced some carbon atoms to precipitate within the $\mathrm{TiC}$ matrix. This phenomenon can be regarded as a beneficial occurrence for the $\mathrm{TiC}$ system in terms of sinterability. As noted earlier, TiC particles are covered by a surface oxide of $\mathrm{TiO}_{2}$, which may impede proper sintering amongst the $\mathrm{TiC}$ particles. The presence of the deposited carbon can locally play as a sintering aid, participating in $\mathrm{TiO}_{2}$ oxide eradication. This can happen through a reaction (Eq. 1) between the precipitated carbon and the $\mathrm{TiO}_{2}$ surface oxide. This equivalence with $\Delta \mathrm{G}^{\mathrm{o}}{ }_{1900}{ }^{\circ} \mathrm{C}$ of almost $-200 \mathrm{~kJ}$ can easily progress under the present SPS circumstances. Therefore, it can be stated that the roughly high relative density of the monolithic $\mathrm{TiC}$ sintered at $1900{ }^{\circ} \mathrm{C}$ may be associated with this occurrence over the sintering route.

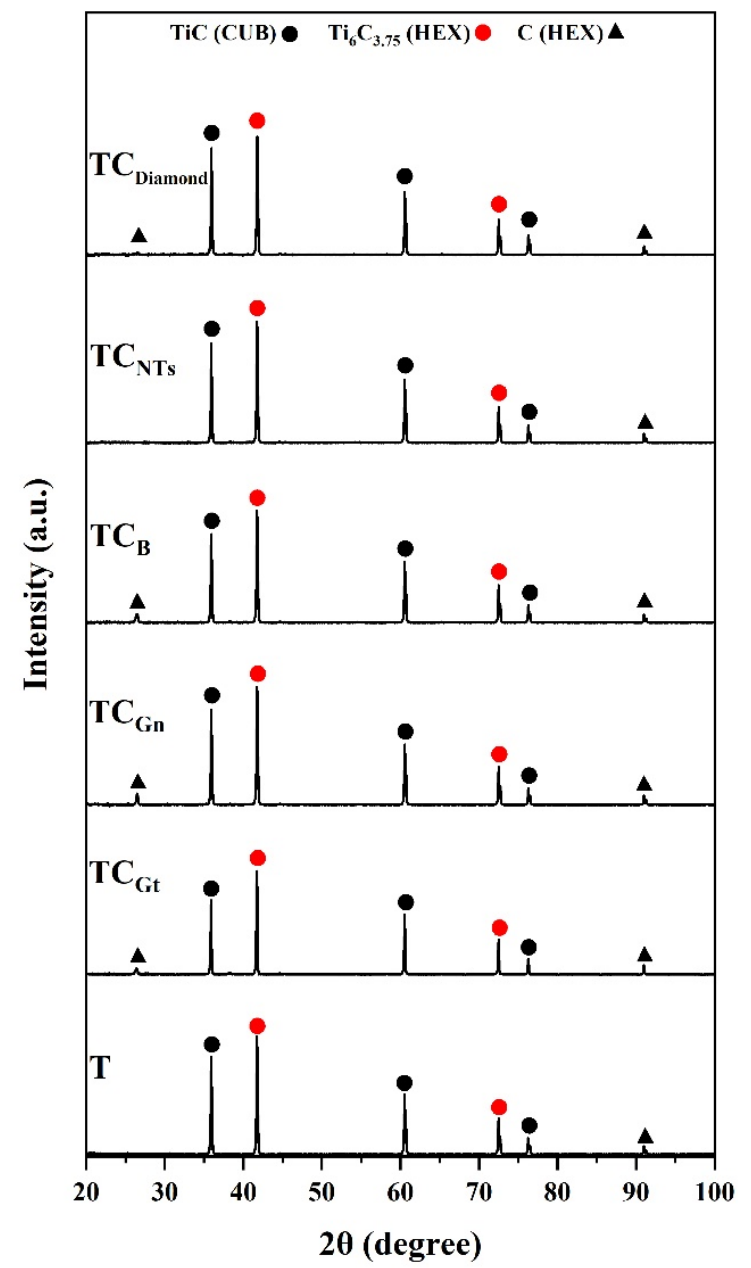

Fig. 2. The $\mathrm{XRD}$ spectra of the $\mathrm{T}, \mathrm{TC}_{\mathrm{Gt}}, \mathrm{TC}_{\mathrm{Gn}}, \mathrm{TC}_{\mathrm{B}}, \mathrm{TC}_{\mathrm{NTs}}$, and $\mathrm{TC}_{\text {Diamond }}$ specimens. 

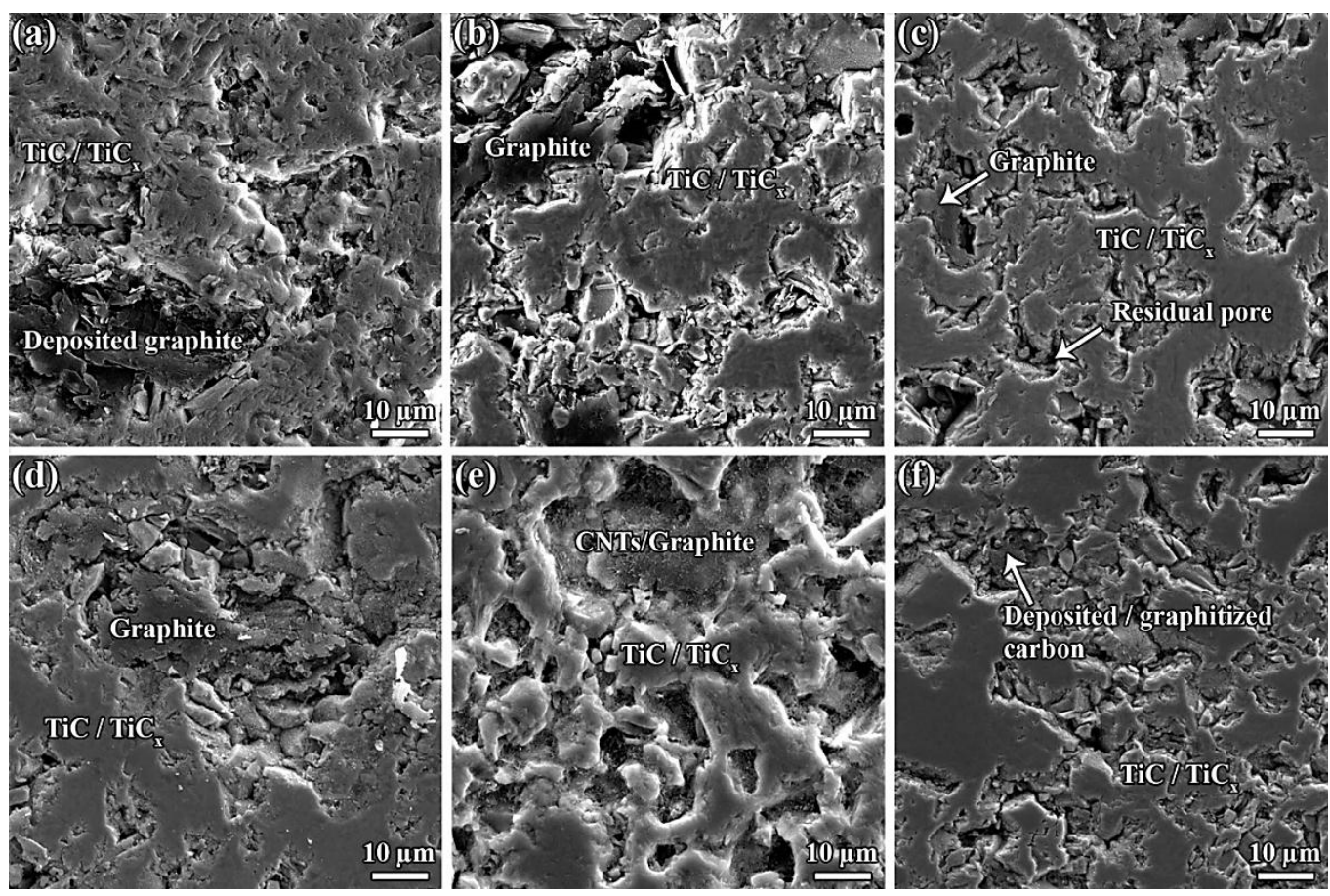

Fig. 3. The FESEM micrographs of (a) $\mathrm{T}$, (b) $\mathrm{TC}_{\mathrm{Gt}}$, (c) $\mathrm{TC}_{\mathrm{Gn}}$, (d) $\mathrm{TC}_{\mathrm{B}}$, (e) $\mathrm{TC}_{\mathrm{NTs}}$, and (f) $\mathrm{TC}_{\text {Diamond }}$ specimens captured on the polished surfaces.

$\mathrm{TiO}_{2}+3 \mathrm{C}=\mathrm{TiC}+2 \mathrm{CO}_{(\mathrm{g})}$

The XRD patterns of the composite samples are approximately similar to that of the monolithic titanium carbide (Fig. 2); despite that, as is clear, a new peak of carbon is emerged at $2 \theta$ of $\sim 27^{\circ}$ in the ceramics doped with graphite, graphene, diamond, and carbon black. Contrary to this similarity in the XRD spectra, and possibly, the role of these carbonaceous phases in $\mathrm{TiO}_{2}$ oxide removal, they had different performance in densifying the composite ceramics. One possible cause might be related to the morphology and particle size. Ignoring the nano-diamond additive, carbon black with particles size of less than 30 $\mathrm{nm}$ was the most efficient additive. This compound could easily play the role of a lubricant over the particle rearrangement stage, and after that, it possibly could occupy the free spaces between the larger TiC particles. Moreover, carbon black is highly active due to its amorphous form, so it could be more efficient in the annihilation of the $\mathrm{TiO}_{2}$ oxide. As a result, the TiC-carbon black composite could reach its full density. Comparing the graphite and graphene additives, it seems that the role of morphology and size was predominant, too. For instance, the possibility of agglomeration could be more severe for the carbon nanotubes compared to other carbonaceous additives, thanks to its morphology. The lower relative density of TiC-CNTs ceramic compared to both TiC-graphite and TiC-graphene could be an endorsement for this assumption. In other words, a uniform distribution of the added carbonaceous phase can be an effective factor, too. When a carbon phase places in the vicinity of a TiC particle, the Eq. 1 can process easily and at low sintering temperatures (over $1288^{\circ} \mathrm{C}$ ). At such low temperature, the released $\mathrm{CO}$ gas can readily leave the bulk. Otherwise, the remaining $\mathrm{TiO}_{2}$ melts at $1843{ }^{\circ} \mathrm{C}$, facilitating its transfer to the areas in which carbonaceous additive is available. The difference, in this case, is the governing densification mechanism at such high temperatures, namely plastic deformation, and as a result, the released gas may be entrapped within the sample, declining the relative density of the composite.

Considering the XRD spectrum of the TiC-diamond sample (Fig. 2), no cubic form of carbon could be identified therein, suggesting a complete graphitization during the SPS process. Diamond, in fact, is a metastable allotrope of carbon that its instability is because of a kinetic issue in rebuilding the structural lattice of diamond. This happening can be diminished remarkably at elevated temperatures [32]. According to the literature, the diamond graphitization can happen at two different temperature ranges of $<1627^{\circ} \mathrm{C}, \mathrm{E}=200 \mathrm{KJ} / \mathrm{mol}$, and $>1627^{\circ} \mathrm{C}, \mathrm{E}=$ $1300 \mathrm{KJ} / \mathrm{mol}$ [33]. Additionally, it was reported that although diamond surface graphitization takes place at almost $700-1400{ }^{\circ} \mathrm{C}$, the intense graphitization will happen at temperatures higher than $1800{ }^{\circ} \mathrm{C}$ [32]. It is true that the diamond particles were the finest powder amongst the used additives; however, it could not contribute to oxide removal before the graphitization phenomenon. So, not only a proportion of the SPS energy was consumed for the diamond graphitization, but also the main part of the oxide removal possibly occurred at temperatures where the produced gas could hardly leave the system.

\subsection{Microstructure assessment}

Fig. 3 compares the polished sections of the titanium carbide-based ceramics produced in this research work. According to the EDS results [28], the microstructure of the undoped TiC (Fig. 3a) is composed of a $\mathrm{TiC} / \mathrm{TiC}_{\mathrm{x}}$ matrix in which graphite is deposited. This observation endorses the earlier result obtained by the XRD analysis. The presence of the roughly big areas of graphite within the TiC matrix suggests this possibility that carbon atoms have intended to deposit where a graphite 
phase was initially nucleated. In short, although the presence of the precipitated graphite is probable at all $\mathrm{TiC}$ grain boundaries, the majority of carbon atoms have preferred to deposit on the initially formed carbon islands.

The microstructures of the samples doped with graphite, graphene, and carbon black (Fig. 3b-d) are approximately similar to that of the T sample (see [26-28] for EDS results). However, it seems that the introduction of a carbonaceous additive has hindered the carbon precipitation from the $\mathrm{TiC}$ matrix to some extent. Considering the micrograph of the TiC-carbon black (Fig. 3d), the graphitization of carbon black is apparent, which was in agreement with the relevant XRD pattern in which only crystalline graphite was detected.

No distinct graphite compound could be observed within the microstructure of the ceramic doped with CNTs. Accordingly, it sounds that the areas in which CNTs were agglomerated could provide preferable places for carbon to precipitate therein. Moreover, as noted earlier, the agglomeration of CNTs can be a main factor participating in decreasing the relative density of the TiC-CNTs composite. As carbon nanotubes have preserved their initial forms, and no bonding has taken place between the tubes, lots of free spaces were entrapped within the agglomerated areas.

Looking at Fig. 3f, it can be seen that the added nano-diamond has been distributed uniformly at the grain boundaries and graphitized therein. As a result, grain boundaries turned to preferable places for carbon atoms to deposit. This explanation justifies why no large area of graphite was formed in this composite.

Fig. 4 exhibits the fractographs of the monolithic titanium carbide and other TiC-based ceramics incorporated by various carbonaceous phases. As can be seen in Fig. 4a, only monolithic TiC contains a considerable amount of residual $\mathrm{TiO}_{2}$. Based on the discussion above, carbon atoms were not uniformly precipitated at the grain boundaries, and consequently, a big proportion of $\mathrm{TiO}_{2}$ content could not be placed in the vicinity of deposited graphite and be reduced to the in-situ TiC. However, the presence of added carbonaceous phase provided this opportunity for this surface oxide to participate in a chemical reaction with the introduced carbon (Eq. 1). Regarding the fracture mode, it seems that all specimens were fractured in a mixed-mode; however, the transgranular fracture had been more dominant in the samples doped with graphite, graphene, and carbon black.

Fig. 5a compares the mean grain size of the $\mathrm{T}$ ceramic and other TiCbased composites. As can be seen, all carbonaceous additives could refine the TiC matrix to some extent. However, carbon black was the most effective additive in grain refining of $\mathrm{TiC}$ so that it could roughly halve the average grain size. On the other side, CNTs were the worst additive in grain refining, decreasing the mean grain size of TiC, just around $15 \%$. The agglomeration of this additive, and consequently, the non-uniform distribution of it within the matrix can be the reason for such a result.

\subsection{Mechanical and thermal properties}

Fig. $4 \mathrm{~b}$ indicates the values of hardness of as-sintered ceramics. Based on this graph, the Vickers hardness of the monolithic titanium carbide was $3128 \mathrm{HV}_{0.1 \mathrm{~kg}}$ that only the introduction of nano carbon black could improve this value, securing a Vickers hardness of $3233 \mathrm{HV}_{0.1} \mathrm{~kg}$. Anyway, other carbonaceous phases decreased this value, amongst which the graphene nanoflakes had the worst impact, reaching a hardness of around $2071 \mathrm{HV}_{0.1 \mathrm{~kg}}$. Considering the effective factors in determining the hardness value in a ceramic-based material, i.e., composition, relative density, and grain size [34], it seems that a combination of the noted items was responsible for these numbers. Since both TiC-graphite and TiC-graphene composites reached the
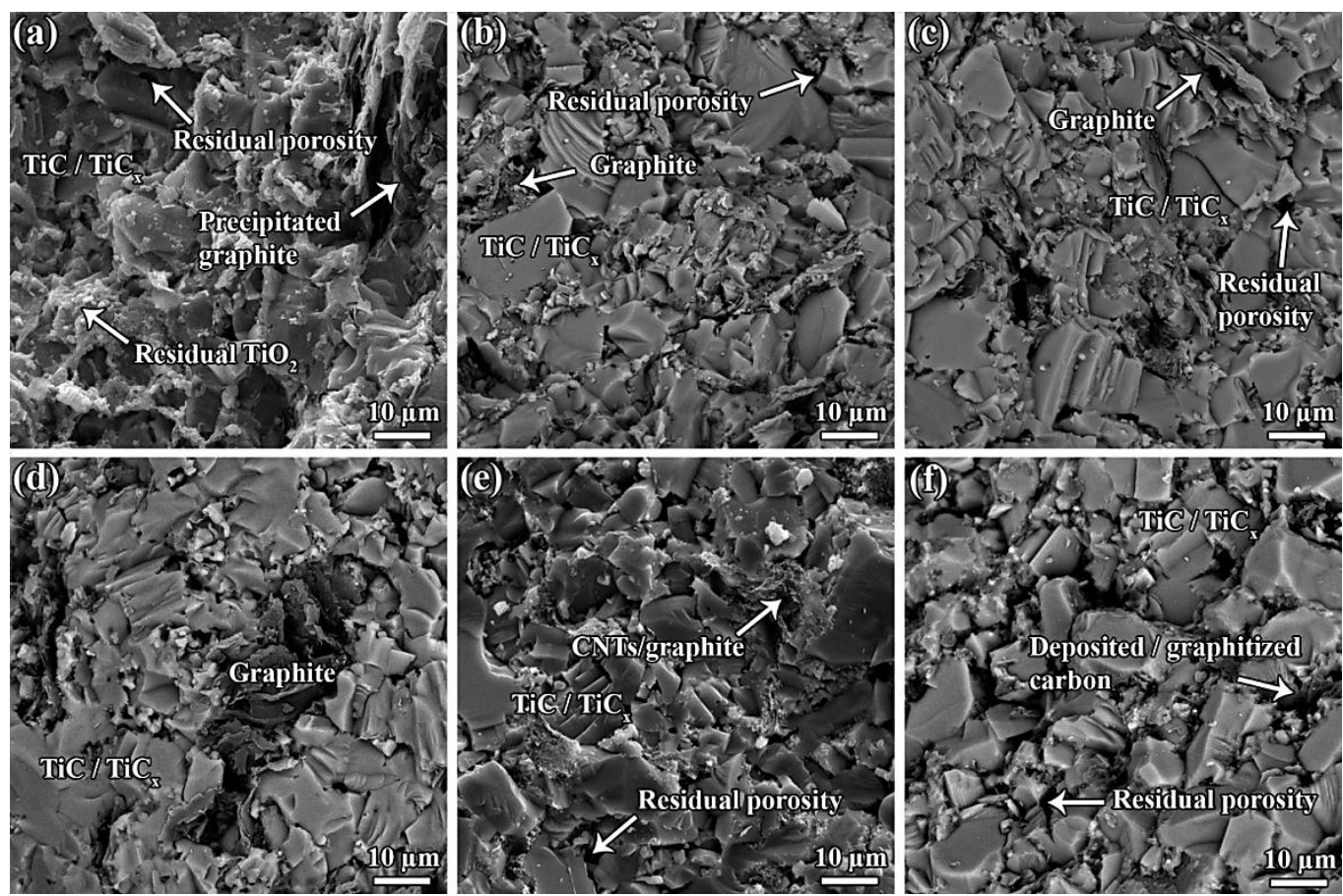

Fig. 4. The FESEM fractographs of (a) $\mathrm{T}$, (b) $\mathrm{TC}_{\mathrm{Gt}}$, (c) $\mathrm{TC}_{\mathrm{Gn}}$, (d) $\mathrm{TC}_{\mathrm{B}}$, (e) $\mathrm{TC}_{\mathrm{NTs}}$, and (f) $\mathrm{TC}_{\text {Diamond. }}$ 

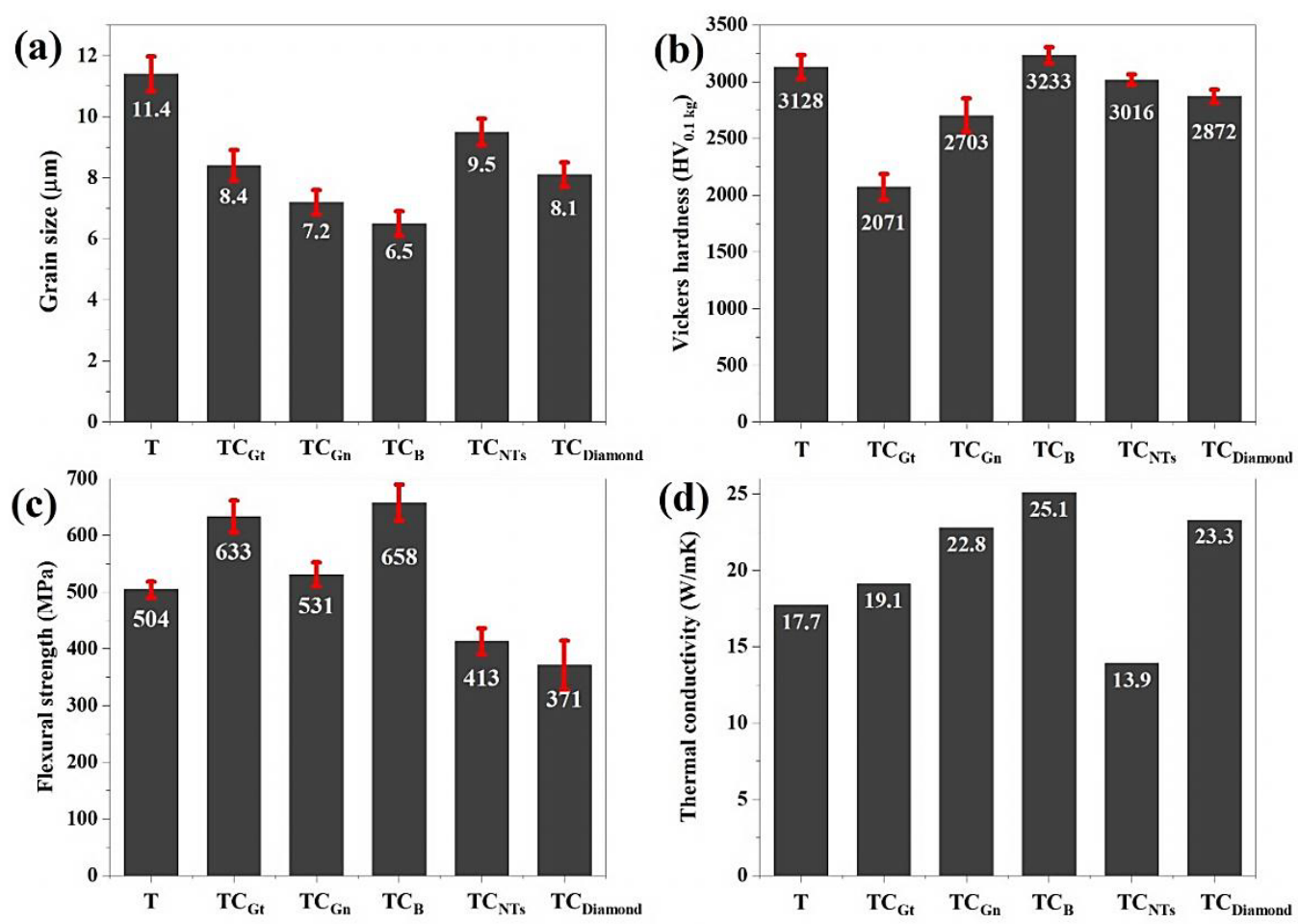

Fig. 5. (a) The mean grain size, (b) hardness, (c) bending strength, and (d) thermal conductivity of $\mathrm{T}, \mathrm{TC}_{\mathrm{Gt}}, \mathrm{TC}_{\mathrm{Gn}}, \mathrm{TC}_{\mathrm{B}}, \mathrm{TC}_{\mathrm{NT}}$, and $\mathrm{TC}_{\mathrm{Diamond}}$ specimens.

lower hardness values in comparison with the TiC-CNTs and TiCdiamond with lower relative densities, it seems that the role of composition was predominant. In other words, the presence of graphite and graphene additives within the $\mathrm{TiC}$ matrix possibly led to more precipitation of carbon, and as a result, lowered hardness values.

Fig. $5 \mathrm{c}$ compares the flexural strength of SPSed ceramics. According to the values presented in this bar chart, the flexural strength of the monolithic TiC was just higher than $500 \mathrm{MPa}$. The addition of graphite, graphene, and carbon black additives was advantageous in strengthening TiC, while the CNTs and nano-diamonds incorporation noticeably lessened bending strength. As the trend of the flexural strength of specimens is completely in harmony with that of the relative density, it sounds that the residual pores performed the key parameter in controlling the strength of the SPSed specimens. Nevertheless, the effect of the composition should not be overlooked. For instance, as noted above, it is possible that more carbon content was deposited within the $\mathrm{TiC}$ matrix in TiC-graphite and TiC-graphene composites; therefore, the toughening/strengthening mechanisms like crack branching, crack deflection, crack bridging, etc. had been more likely to be activated in these samples.

Finally, the thermal conductivity of the ceramics is compared in Fig. 5 d. All additives could improve the thermal conductivity of TiC apart from CNTs. Amongst these carbonaceous phases, the influence of carbon black was the most significant, resulted in thermal conductivity of $25.1 \mathrm{~W} / \mathrm{mK}$, followed by the TiC-graphene and TiC-diamond samples with the thermal conductivity of almost $23 \mathrm{~W} / \mathrm{mK}$. Based on the literature, thermal conductivity in composites is mostly controlled by residual pores, grain boundaries, secondary phases, and point defects [35]. The TiC-diamond had the lowest relative density value compared to other ceramics, but as explained earlier, the homogenous distribution of it at the grain boundary of the TiC matrix, and graphitization of it therein, led to the development of a continuous network of graphite within the whole sample. As the graphite phase has a considerably larger thermal conductivity than the titanium carbide [27], this net of graphite at the grain boundaries could contribute to improving the overall thermal conductivity.

\section{Conclusion}

The influence of various carbonaceous phases on the microstructural evolution, mechanical-physical properties, and sinterability of $\mathrm{TiC}$ was examined in this research. All ceramics were SPSed at the same sintering circumstances at $1900{ }^{\circ} \mathrm{C}$ under $40 \mathrm{MPa}$ for $600 \mathrm{~s}$. A relative density of $100 \%$ was gained when carbon black was used as the sintering aid. On the contrary, the nano-diamonds had the worst impact on the relative density of $\mathrm{TiC}$, resulting in around $10 \%$ residual porosity. Although the microstructure of all samples comprised of the $\mathrm{TiC}$ and carbonaceous phases, some of these forms of carbon impeded the carbon precipitation to some extent. Additionally, the introduced additives got the preferable beds for the carbon atoms to deposit therein. Amongst the examined carbon additives, carbon black contributed the most to grain refining of titanium carbide. Finally, the highest values of hardness (3233 $\mathrm{HV}_{0.1 \mathrm{~kg}}$ ), bending strength $(658 \mathrm{MPa})$, and thermal conductivity $(25.1 \mathrm{~W} / \mathrm{mK})$ were promised for the ceramic doped with $5 \mathrm{wt} \%$ carbon black.

\section{Data availability}

The raw/processed data required to reproduce these findings cannot be shared at this time due to technical or time limitations. 


\section{References}

[1] F. Behboudi, M. Ghassemi Kakroudi, N.P. Vafa, M. Faraji, S.S. Milani, Molten salt synthesis of in-situ TiC coating on graphite flakes, Ceram Int. 47 (2021) 8161-8168.

[2] N. Sadeghi, H. Aghajani, M.R. Akbarpour, Microstructure and tribological properties of in-situ $\mathrm{TiC}-\mathrm{C} / \mathrm{Cu}$ nanocomposites synthesized using different carbon sources (graphite, carbon nanotube and graphene) in the $\mathrm{Cu}$-Ti-C system, Ceram Int. 44 (2018) 22059-22067.

[3] W. Handoko, F. Pahlevani, I. Emmanuelawati, V. Sahajwalla, Transforming automotive waste into $\mathrm{TiN}$ and $\mathrm{TiC}$ ceramics, Mater Lett. 176 (2016) 17-20.

[4] Y. Ma, C. Bao, S. Song, J. Lei, Effects of TiC addition on microstructures, mechanical properties and fracture behaviors of porous titanium carbide ceramics, Ceram Int. 44 (2018) 1991919925

[5] C. Magnus, T. Kwamman, W.M. Rainforth, Dry sliding friction and wear behaviour of TiC-based ceramics and consequent effect of the evolution of grain buckling on wear mechanism, Wear. 422-423 (2019) 54-67.

[6] M. Zhang, M. Li, J. Chi, S. Wang, L. Ren, M. Fang et al., Microstructure evolution, recrystallization and tribological behavior of TiC/WC composite ceramics coating, Vacuum. 166 (2019) 64-71.

[7] X. Zhou, Z. Liu, Y. Li, Y. Li, P. Li, F. Huang et al., SiC ceramics joined with an in-situ reaction gradient layer of $\mathrm{TiC} / \mathrm{Ti} 3 \mathrm{SiC} 2$ and interface stress distribution simulations, Ceram Int. 44 (2018) $15785-15794$

[8] J.X. Xue, J.X. Liu, G.J. Zhang, H.B. Zhang, T. Liu, X.S. Zhou et al., Improvement in mechanical/physical properties of TiC-based ceramics sintered at $1500{ }^{\circ} \mathrm{C}$ for inert matrix fuels, Scr Mater. 114 (2016) 5-8.

[9] Y. Ma, C. Bao, L. Han, J. Chen, Study on Microstructures and Properties of Porous TiC Ceramics Fabricated by Powder Metallurgy, J Mater Eng Perform. 26 (2017) 636-43.

[10] A. Yazdani, M. Soltanieh, H. Aghajani, S. Rastegari, Deposition of Nano Sized Titanium Nitride on H11 Tool Steel Using Active Screen Plasma Nitriding Method, J Nano Res. 11 (2010) 79-84.

[11] W. Gao, Y. Zhou, X. Han, S. Li, Z. Huang,. Preparation and microstructure of 3D framework TiC-TiB2 ceramics and their reinforced steel matrix composites, Ceram Int. 47 (2021) 2329-2337.

[12] Y. Gu, J.X. Liu, Y. Wang, J.X. Xue, X.G. Wang, H. Zhang et al., Corrosion behavior of $\mathrm{TiC}-\mathrm{SiC}$ composite ceramics in molten FLiNaK salt, J Eur Ceram Soc. 37 (2017) 2575-2582.

[13] A. Baux, L. Nouvian, K. Arnaud, S. Jacques, T. Piquero, D. Rochais et al., Synthesis and properties of multiscale porosity $\mathrm{TiC}-\mathrm{SiC}$ ceramics, J Eur Ceram Soc. 39 (2019) 2601-2616.

[14] M.S. Oskooie, M.S. Motlagh, H. Aghajani, Surface properties and mechanism of corrosion resistance enhancement in a high temperature nitrogen ion implanted medical grade Ti, Surf Coatings Technol. 291 (2016) 356-364.

[15] L.K. Foong, B.H. Jume, C. Xu, Densification behavior and mechanical properties of hot-pressed $\mathrm{TiC}-\mathrm{WC}$ ceramics, Ceram Int. 46 (2020) 28316-28323.

[16] R. Eatemadi, Z. Balak, Investigating the effect of SPS parameters on densification and fracture toughness of $\mathrm{ZrB} 2-\mathrm{SiC}$ nanocomposite. Ceram Int. 45 (2019) 4763-4770.

[17] Z. Balak, Shrinkage, hardness and fracture toughness of ternary $\mathrm{ZrB} 2-\mathrm{SiC}-\mathrm{HfB} 2$ composite with different amount of HfB2. Mater, Chem Phys. 235 (2019) 121706.
[18] K. Kavakeb, Z. Balak, H. Kafashan, Densification and flexural strength of $\mathrm{ZrB} 2-30 \mathrm{vol} \% \mathrm{SiC}$ with different amount of HfB2, Int J Refract Met Hard Mater. 83(2019) 104971.

[19] E. Akbari, M. Ghassemi Kakroudi, V. Shahedifar, Investigation of production parameters in fracture behavior of hot-pressed $\mathrm{Al} 2 \mathrm{O} 3$ $\mathrm{SiC} /$ graphite fibrous monolithic ceramics: Fibers orientation and cell boundary fraction, Int J Appl Ceram Technol. 16(2019) 1329-1336.

[20] E. Akbari, Ghassemi M. Kakroudi, V. Shahedifar, H. Ghiasi, The influence of different $\mathrm{SiC}$ amounts on the microstructure, densification and mechanical properties of hot-pressed A12O3-SiC composites, Int J Appl Ceram Technol. 17 (2019) 491-500.

[21] A. Yazdani, M. Soltanieh, H. Aghajani, Structural and mechanical evaluation of deposited nano structured TiN coating using active screen plasma nitriding technique, Eur Phys J Appl Phys. 65 (2014) 20801.

[22] L. Liu, B. Wang, X. Li, Q. He, L. Xu, X. Cao et al., Liquid phase assisted high pressure sintering of dense TiC nanoceramics, Ceram Int. 44 (2018) 17972-17977.

[23] M.S. Shakeri, H. Aghajani, Modeling of stress relaxation process, case study: Shape setting heat treatment of a Ni rich-NiTi alloy, J Alloys Compd. 574(2013) 119-123.

[24] Y. Tan, H. Cai, X. Cheng, Z. Ma, Z. Xu, Z. Zhou, Microstructural and mechanical properties of in-situ micro-laminated $\mathrm{TiC} / \mathrm{Ti}$ composite synthesised, Mater Lett. 228 (2018) 1-4.

[25] Y. Liu, Y. Li, F. Luo, X. Su, J. Xu, J. Wang et al., Mechanical, dielectric and microwave absorption properties of $\mathrm{TiC} /$ cordierite composite ceramics, J Mater Sci Mater Electron. 28 (2017) 1211512121

[26]T.P. Nguyen, Y. Pazhouhanfar, S.A. Delbari, Q.V. Le, S. Shaddel, M. Pazhouhanfar et al., Characterization of spark plasma sintered TiC ceramics reinforced with graphene nano-platelets, Ceram Int. 46 (2020) 18742-18749.

[27] M. Fattahi, A. Babapoor, S.A. Delbari, Z. Ahmadi, A. Sabahi Namini, M. Shahedi Asl, Strengthening of TiC ceramics sintered by spark plasma via nano-graphite addition, Ceram Int. 46 (2020) 12400-12408

[28] V.H. Nguyen, Y. Pazhouhanfar, S.A. Delbari, S. Shaddel, A. Babapoor, Y. Mohammadpourderakhshi et al., Beneficial role of carbon black on the properties of TiC ceramics, Ceram Int. 46 (2020) 23544-23555.

[29] C.C. Jiang, T. Goto, T. Hirai, Microhardness of non-stoichiometric TiCx, plates prepared by chemical vapour deposition, J Less Common Met. 163 (1990) 339-346.

[30] M. Shahedi Asl, Z. Ahmadi, A. Sabahi Namini, A. Babapoor, A. Motallebzadeh, Spark plasma sintering of $\mathrm{TiC}-\mathrm{SiCw}$ ceramics, Ceram Int. 45 (2019) 19808-19821.

[31] D. Vallauri, I.C. Atías Adrián, A. Chrysanthou, TiC-TiB2 composites: A review of phase relationships, processing and properties, J Eur Ceram Soc. 28 (2008) 1697-1713.

[32] L.J. De Oliveira, S.C. Cabral, M Filgueira., Study hot pressed Fediamond composites graphitization, Int Journal of Refractory Metals and Hard Materials.35 (2012) 228-234.

[33] W.Z. Shao, V.V. Ivanov, L. Zhen, Y.S. Cui, Y. Wang, A study on graphitization of diamond in copper-diamond composite materials, Materials Letters. 58 (2003) 146-149.

[34] S. Shaddel, A. Sabahi Namini, Y. Pazhouhanfar, S.A. Delbari, M. Fattahi, M. Shahedi Asl, A microstructural approach to the chemical reactions during the spark plasma sintering of novel TiC-BN ceramics, Ceram Int. 46 (2020) 15982-15990.

[35] A. Babapoor, M. Shahedi Asl, Z. Ahmadi, A. Sabahi Namini, Effects of spark plasma sintering temperature on densification, hardness and thermal conductivity of titanium carbide, Ceram Int. 44 (2018) 14541-14546. 